\title{
MEASUREMENT OF NEUTRON SPATIAL DISTRIBUTION OF THE BNCT EPITHERMAL BEAM AT THE REACTOR LVR-15
}

\author{
Michaela Rabochováa,*, Miroslav Vinš ${ }^{b}, J_{\text {AROslav Šoltés }}^{b}$, \\ BoŽEnA MichalCOVÁc
}

${ }^{a}$ Faculty of Electrical Engineering, Czech Technical University in Prague, Czech Republic

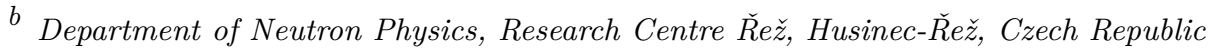

${ }^{c}$ Department of Neutronography Processing, Nuclear Physics Institute of the CAS, Husinec- Řez, Czech Republic

* corresponding author: michaela.rabochova@seznam.cz

\begin{abstract}
In this study, a measurements of neutron field using a special positioning device with a ${ }^{6} \mathrm{Li}+\mathrm{Si}$ detector and image plate is described. The measurements were provided for Boron Neutron Capture Therapy (BNCT) channel of the LVR-15 reactor in the Research Centre Rez Ltd., Czech Republic. Mapping of neutron field represents an essential and crucial part of planning BNCT treatment (especially for patients suffering from brain tumor Glioblastoma Multiforme).
\end{abstract}

KEYWORDS: BNCT, map of neutron field, ${ }^{6} \mathrm{Li}+\mathrm{Si}$ detector, positioning device.

\section{INTRODUCTION}

Glioblastoma multiforme [1, 4 is the most common malignant radio-resistant and chemoresistant tumor of the central nervous system which has been incurable for decades and even today, unfortunately, the prognosis is not favorable [5]. This type of tumor is characterized by very fast growth and aggressive invasion to the surrounding normal brain tissue. It is very difficult to remove all of the affected tumor cells without serious damage of the brain. Despite the advanced diagnostics (especially in neuroimaging), and various multimodal therapies that include surgical resection followed by radiation therapy (and alternatively chemotherapy) still remains a considerable problem with finding efficient and gentle treatment of the sensitive area of brain tissue. In this regard, Boron Neutron Capture Therapy (BNCT) is unique selective radiotherapy based on capture of non-radioactive nuclide ${ }^{10} \mathrm{~B}$ by cancer cells and the subsequent capture of thermal neutrons resulting in the nuclear reaction ${ }^{10} \mathrm{~B}(\mathrm{n}, \alpha){ }^{7} \mathrm{Li}$. These products of reaction selectively damage cancer cells while healthy tissue is spared of radiation load.

An absolutely essential part of the treatment planning is determination of parameters and proper setting of correct compensation of neutron beam. The purpose of this project was to measure the spatial distribution of neutrons inside the epithermal horizontal channel of the research reactor LVR-15 (the Research Centre Rez Ltd., Czech Republic) [6], which is used for the method of Boron Neutron Capture Therapy.

\section{RESEARCH BACKGROUND}

\subsection{The SPECIAL POSITIONING DEVICE}

The mapping of neutron beam was done by using a special positioning device which fixed a Si semiconductor detector with ${ }^{6} \mathrm{Li}$ converter. The positioning device can moves the detector in three axis and it basically consists of a specially modified support frame with three engines. The special positioning device is shown in Fig. 1 .

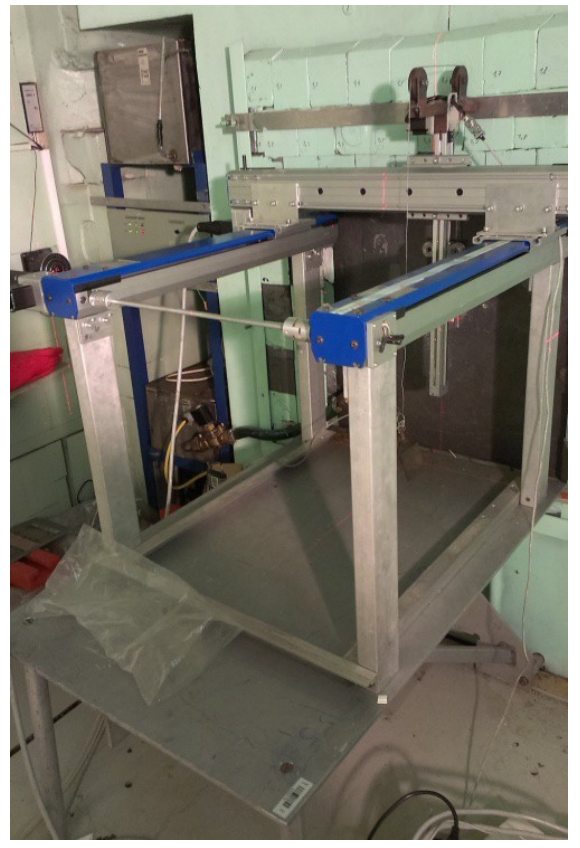

FIGURE 1. The special positioning device.

\section{2. ${ }^{6} \mathrm{LI}+$ Si DETECTOR}

For the spatial mapping of neutron beam was used a detector which was consisted of ${ }^{6} \mathrm{Li}$ converter and Si semiconductor detector [7]. The ${ }^{6} \mathrm{Li}$ converter provided a production of ${ }^{3} \mathrm{H}$ (after its insertion into neutron flux $)$ via ${ }^{6} \mathrm{Li}(\mathrm{n}, \alpha)^{3} \mathrm{H}$ reaction. The total energy of the reaction is $4.78 \mathrm{MeV}\left(2.73 \mathrm{MeV}\right.$ for ${ }^{3} \mathrm{H}$ and $2.05 \mathrm{MeV}$ for $\alpha$ particle). The tritium ${ }^{3} \mathrm{H}$ is then detected in a $\mathrm{Si}$ detector. The active diameter of ${ }^{6} \mathrm{Li}$ 
converter is $3 \mathrm{~mm}$; the case of Si detector has diameter $25 \mathrm{~mm}$. The distance between converter and detector is approximately $8 \mathrm{~mm}[8]$. The scheme of the detector is shown in Fig. 2 .

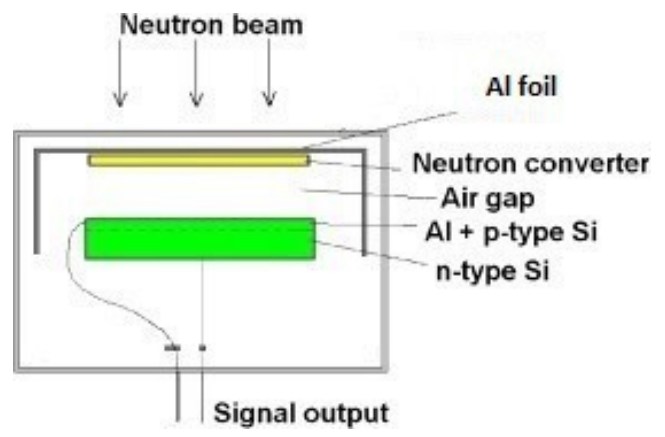

Figure 2. The scheme of ${ }^{6} \mathrm{Li}+\mathrm{Si}$ detector [8].

\subsection{The IMAGE PLATE}

Another method that has been performed is the experimental determination of the intensity distribution excitations caused by neutron beam by means of the image plates (Fig. 3). Displaying the neutron flux through the imaging plate is mainly used for neutron radiography method. The principle is based on passing the neutron beam through an object and its subsequent detection on the imagine plate. The result is a $2 \mathrm{D}$ (or $3 \mathrm{D}$ ) image of the different intensities of the neutron flux which is determined by the absorption properties of the object material. In the case of the experiment mentioned in this work was used this method by the same way, but not for displaying a particular subject, but purely for displaying the parameters of the neutron beam intensities.

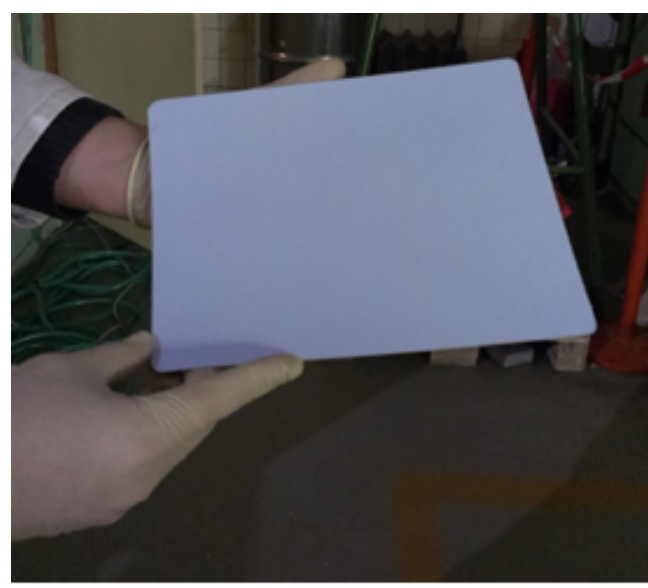

Figure 3. The image plate.

\section{Method of Measurement}

\subsection{The Mesaurement With the POSITIONING DEVICE}

The measurement was carried out from March 31 to April 1, 2016 in front of the horizontal channel BNCT of the research nuclear reactor LVR-15 in the Research
Centre Rez Ltd. The acquisition of the data was based on communication between GENIE-2000 program (detector) and special positioning device utility program. The getting device to work was accomplished by sequential modifications of batch codes. The codes control position of the positioning device and also provide a record of the data of measurements. The main aim of this measurement was to determine the spatial distribution of neutron beam, which is important to verify its homogeneity for subsequent applications of BNCT. The map of the route of detector was created and loaded into the control position program of positioning device. The movement of positioning device with ${ }^{6} \mathrm{Li}+\mathrm{Si}$ detector was determined with fixed increments of $1 \mathrm{~cm}$ along the horizontal axis $\mathrm{y}$ and along the vertical axis $\mathrm{z}$. The time of measurement was $\sim 4$ minutes for every position of detector. The scheme of route of the detector is shown in Fig. 4

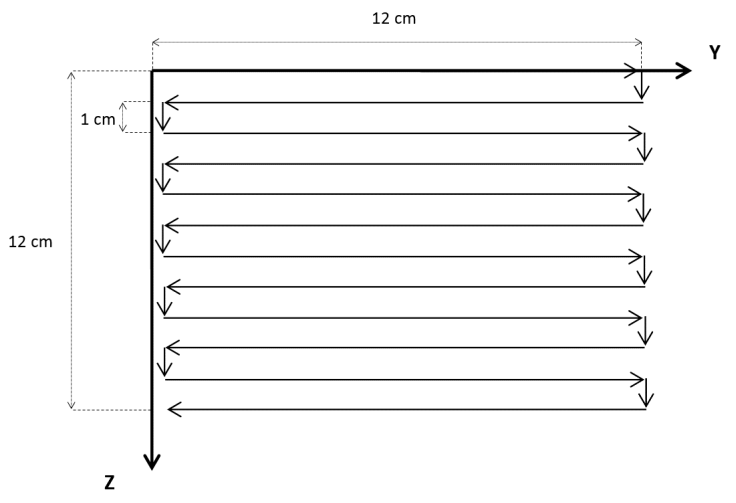

FigurE 4. The scheme of the route of ${ }^{6} \mathrm{Li}+\mathrm{Si}$ detector.

The entire measurement lasted 9 and $\frac{1}{2}$ hours (240 second for one position) and data from detector were analyzed with the software GENIE-2000 by CANBERRA Company 9].

The resulting peak areas of ${ }^{3} \mathrm{H}$ have to be corrected for the change in reactor power as the power was not stable during whole measurement. The power of reactor was higher at the beginning of measurement. For the time of the correction was used the data from ionization chambers which monitoring the BNCT channel (see Fig. 5).

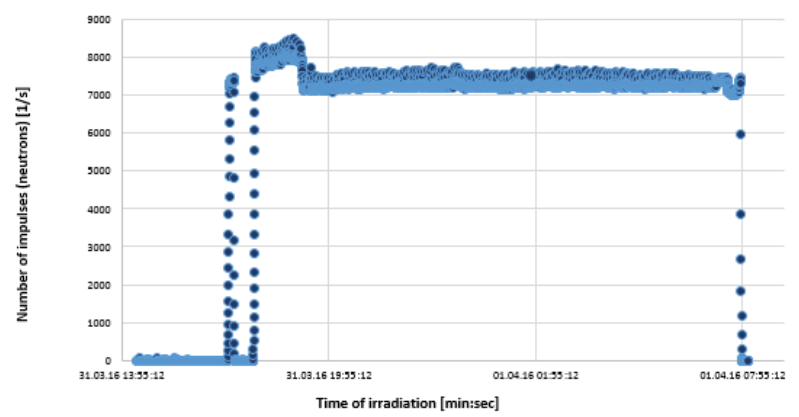

Figure 5. The development of reactor power. 
The resulting peak areas after correction were calculated based on the following relationship

$$
S_{\mathrm{pk}}=\frac{M}{x_{i}} S_{\mathrm{p}}
$$

where $S_{\mathrm{pk}}$ denotes the peak area after correction, $M$ is a median of the numbers of pulses during irradiation, $x_{i}$ is an arithmetic average of the numbers of pulses during the $i$-th interval of irradiation in a given position and $S_{\mathrm{p}}$ is the peak area.

\subsection{The measurement With image Plate}

The second experiment of mapping neutron field was performed on April 21, 2016. The main aim was to take a radiography image of thermal neutron beam and its evaluation using neutron imaging plate. The plate was placed under the outlet of the neutron beam. All manipulation were done by hand, the image plate was moved to the beam exit after the beam was opened. This system was provided for pulling the plate upward for start measuring so that the enter of the channel was subsequently overlapped and after the end of irradiation the plate was pull down to the start position. This principle was chosen in order to avoid an unwanted exposure during opening and closing the BNCT horizontal channel. Start experimental position of image plate is shown in Fig. 6. Overall exposure time was 2 minutes.

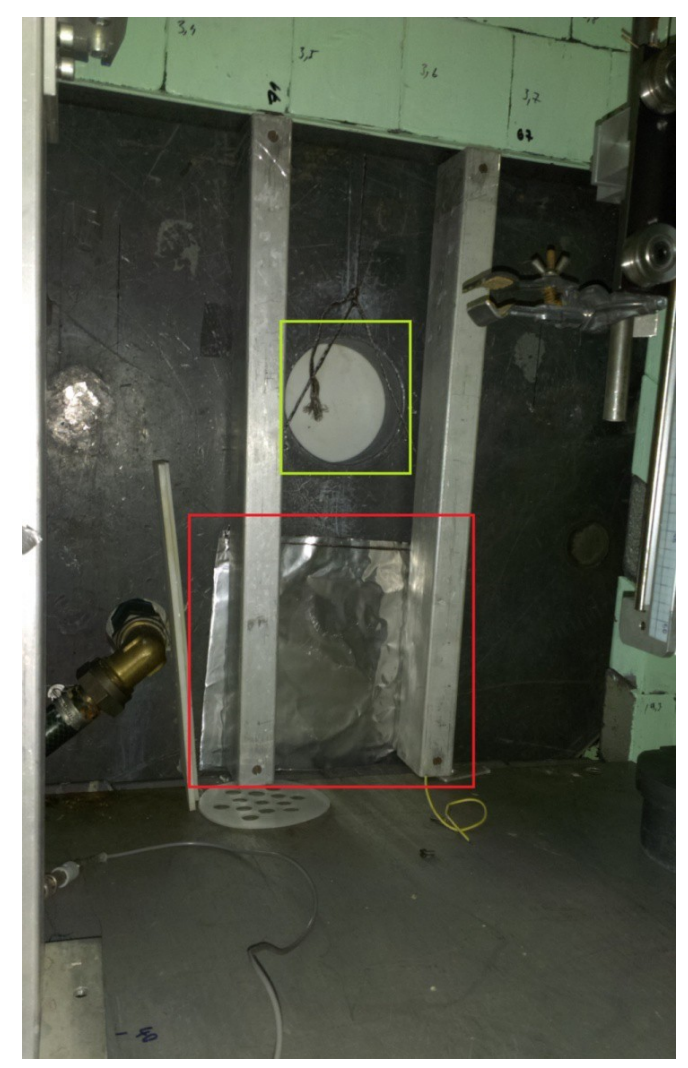

FiguRE 6. The neutron image plate (in the red frame) located in the default position below the enter of the BNCT horizontal channel (green frame).
After the irradiation, the plate was evaluated at the Institute of Nuclear Physics Institute of the CAS in Rez. Subsequently, the measured data was processed by the device FUJIFILM BAS-1800 (BAS - Bioimaging Analyzer System), which evaluated the measured intensity.

\section{Result of Measurement}

\subsection{The mesaurement With the POSITIONING DEVICE}

Based on neutron beam radiation of ${ }^{6} \mathrm{Li}+\mathrm{Si}$ detector the map of thermal neutron flux distribution was obtained (Fig. 7). Values within each field represents the value of the peak area.

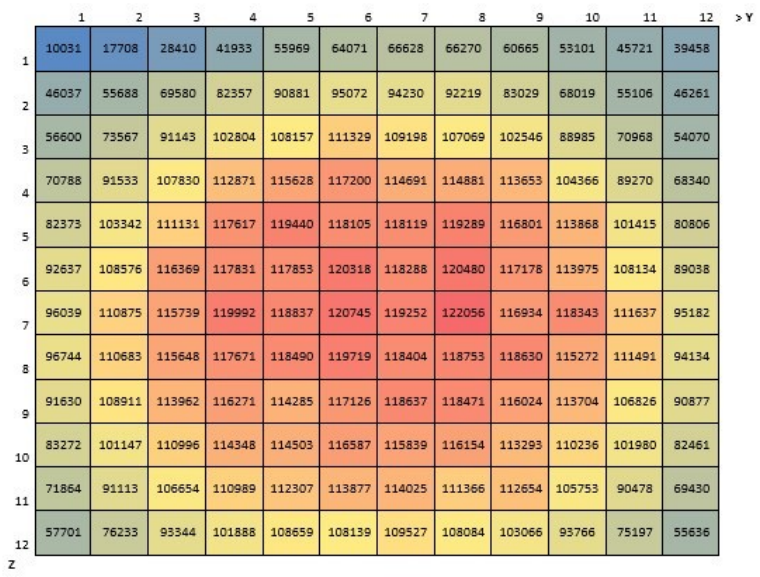

FIGURE 7. The map of neutron flux distribution.

The graphical representation of the measured data is on the Fig. 8. The axis $\mathrm{x}$ represents the values of the peak areas of ${ }^{3} \mathrm{H}$ and the axes $\mathrm{y}$ and $\mathrm{z}$ are the positions. The measurement uncertainty was around $1 \%$.

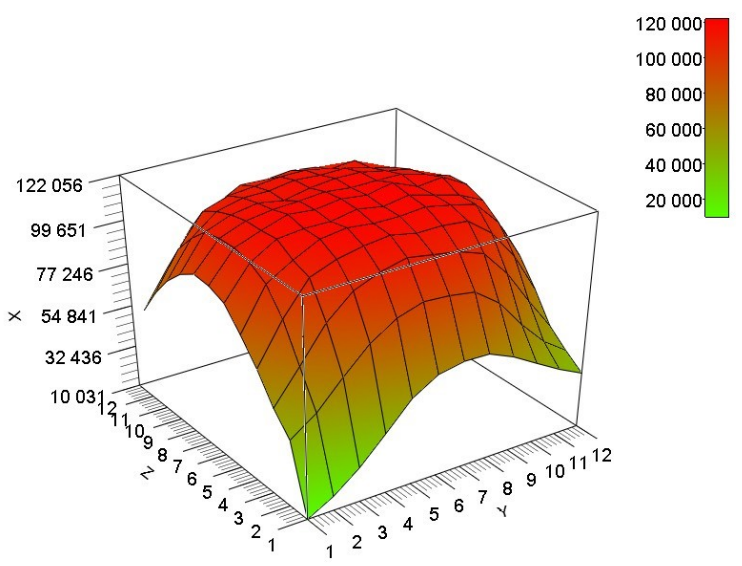

FIGURE 8. 3D graph of neutron flux distribution.

\subsection{The measurement With image plate}

The measured neutrogram of the neutron beam of reactor LVR-15 was then rendered Fig. 9 


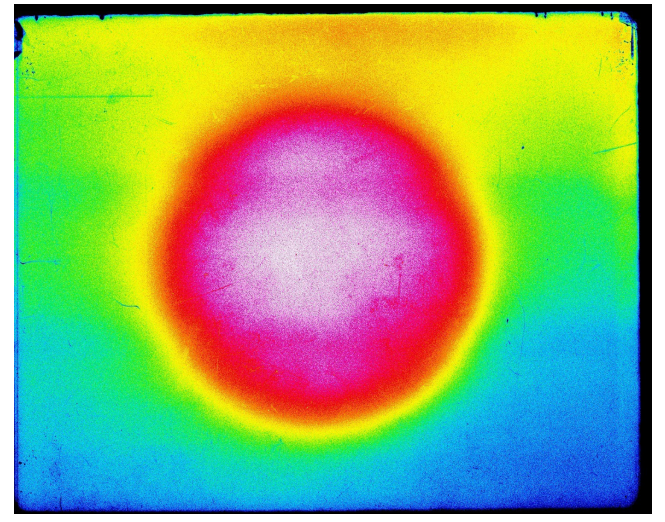

FiguRE 9. The neutrongram of neutron beam.

The neutron beam is seen here as a red-edge circle. The dark blue color represents the lowest level of excitation (the largest decline), while the white color represents the high intensity. On the neutrongram are partially visible muffled two horizontal bars in the upper and lower half, which are dependent on the properties of a neutron plate and therefore do not reflect the actual intensity values at those locations. Unfortunately it is not possible to suppress this phenomenon. Small local changes in intensity are the result of small surface scratch of the plate. On the picture is evident symmetrical circular beam (red-purple-white colored intensity) with the lowest attenuation values in the centre, as one might expect. However, the upper half of the image shows a higher level of exposure than the lower half. Possible in this case, this could be the influence of gamma radiation to which the neutron plate can be also sensitive. This impact would be affected by the opening BNCT channel. Another additional measurements intended to clarify these results are planned. It is possible to plot a 3D graph (Fig. 10).

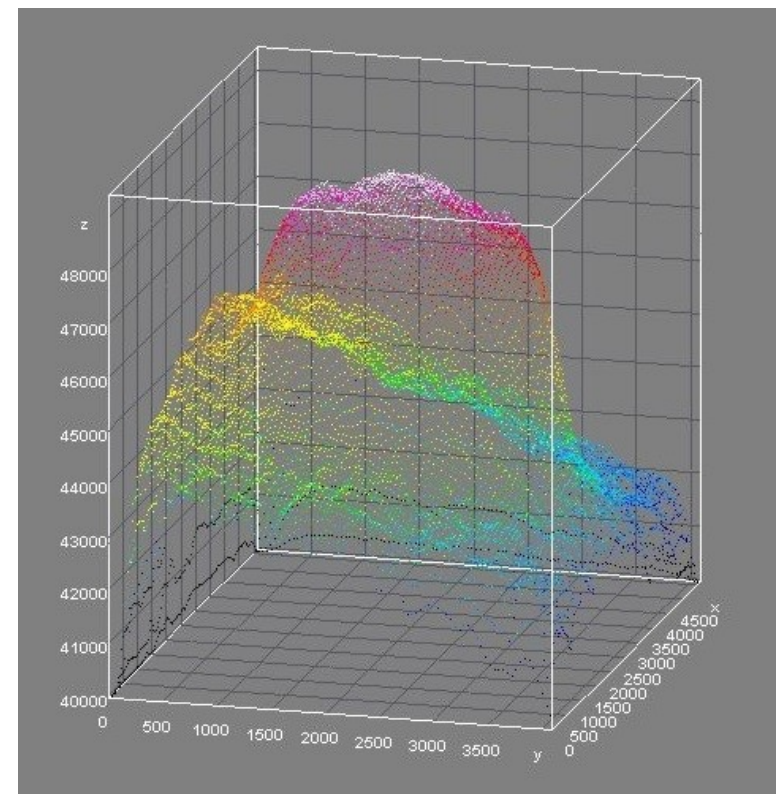

FiguRE 10. 3D neutrogram of neutron beam.
The values on the axes $\mathrm{x}, \mathrm{y}$ represent the pixel, resp. one unit corresponds to one pixel, which is equivalent to 50 micrometers. Thus e.g. $500 \mathrm{px}=2.5 \mathrm{~cm}, 1000 \mathrm{px}$ $=5 \mathrm{~cm}, 2000 \mathrm{px}=10 \mathrm{~cm}$ etc. The $\mathrm{z}$ axis is then plotted excitation intensities in individual pixels. The values are relative and they do not represent actual neutron flux density. The point $[\mathrm{x}, \mathrm{y}]=[0,0]$ represents the upper-left corner of the neutron plate placed looking towards the enter of the horizontal channel. Again, this graph shows the slope, which is probably caused again by the opening of the channel.

\section{Conclusions}

The measurement results show that the profile of the beam is quite homogeneous in its whole crosssection without any significant peaks. In the future, other measurements with other types of converter are planned. Also properly functionality of special positioning system which fixed the ${ }^{6} \mathrm{Li}+\mathrm{Si}$ detector was confirmed.

The measurement using neutron image plates showed that the neutron beam is symmetrical with the highest intensity in the centre of the beam. It was detected intensity changes in the upper half of the image compared to the lower half of the image. This situation may be caused by the influence of unwanted exposure during opening horizontal channel or by unwanted exposure of gamma radiation at the opening horizontal channel.

Both methods were sensitive to thermal neutrons (i.e. ${ }^{6} \mathrm{Li}$ converter and $\mathrm{Gd}$ layer of neutron image plate).

Both experiments confirmed the symmetry of the neutron beam of BNCT horizontal channel of LVR-15 reactor.

\section{ACKNOWLEDGEMENTS}

The presented work was financially supported by the Ministry of Education, Youth and Sport Czech Republic Project LQ1603 (Research for SUSEN).

\section{REFERENCES}

[1] K. Urbánek. Nádory mozku: gliomy - astrocytom, glioblastoma, příznaky, léčba, diagnostika, 2008. http://www.zbynekmlcoch.cz/informace/medicina/ neurologie-nemoci-vysetreni/nadory-mozkugliomy-astrocytom-glioblastom-priznaky-lecbadiagnostika-prognoza

[2] H. Biliková, P. Buzrla, J. Dvořáčková. Problematika mozkových nádorů astrogliální řady. European Journal for Biomedical Informatic 6(1):cs3-cs7, 2010. http://www.ejbi.org/en/ejbi/article/9-csproblematika-mozkovych-nadoru-astroglialnirady.html.

[3] M. M. Abd-El-Barr, E. A. Chiocca. How much is enough? The question of extent of resection in glioblastoma multiforme. World Neurosurgery 82:e109-e110, 2014. DOI:10.1016/j.wneu.2014.05.006 
[4] A. Phuphanich. Glioblastoma y astrocitoma maligno. American Brain Tumor Association, 2012. http://www.abta.org/resources/spanish-languagepublications/glioblastoma-y-astrocitomamaligno.pdf

[5] S. S. Stylli, A. H. Kaye, L. MacGregor, et al. Photodynamic therapy of high grade glioma - long term survival. J Clin Neurosci 12(4):389-398, 2005. DOI:10.1016/j.jocn.2005.01.006

[6] J. Burian. LVR-15 reactor - Applications of neutron beam in medicine, biology, dosimetry. IAEA Technical Meeting lecture, Vienna, Austria, 2011.

[7] L. Viererbl, J. Šoltés, M. Vinš, et al. Measurement of thermal neutron beam parameters in the LVR-15 research reactor. In Transaction of IGORR 2013 conference. 2013. http://www.igorr.com/home/ liblocal/docs/IGORR2013/07_1001.pdf

[8] L. Viererbl, J. Burian, S. Hladky, et al. Si diode with converter used for measurement of epithermal neutron beam of LVR-15 reactor. Nuclear Instruments and Methods in Physics Research Section A: Accelerators, Spectrometers, Detectors and Associated Equipment 580(1):366-368, 2007. DOI:10.1016/j.nima.2007.05.180

[9] Canberra Industries, Inc. Genie 2000 basic spectroscopy software, 2016. http://www. canberra. com/products/radiochemistry_lab/pdf/G2KBasicSpect-SS-C40220.pdf. 